\title{
A história dos estudos da religião importa para a Ciência da Religião?
}

\author{
Ivan Strenski* \\ tradução de Fábio L. Stern**
}

Tradução gentilmente autorizada pelo autor. Texto de uma palestra sobre os desafios metodológicos na construção da história da ciência da religião, originalmente publicado como capítulo do livro Człowiek Wartości (KOMENDERY, A.; PADOA, R.; MICHA'A ZLIWY (Eds.). Cztowiek Wartości. Cracóvia: Wydawnictwo Naukowe WSP, 1997, pp. 146-156). Visto a preocupaçáo nos últimos três anos de pesquisadores da ciência da religião brasileira em levantar a história da disciplina no Brasil, a discussão de Strenski se apresenta como um contraponto internacional importante sobre como construir uma história correta dos estudos da religião.

Se a história dos estudos da religião não importa para a ciência da religião, podemos muito bem rasgar nossos diplomas. Como poderia a história dos estudos sobre a religiáo náo ter algo a ver com a ciência da religião em si? Como é possível a qualquer ser pensante que se preze na ciência da religião perseguir objetivos acadêmicos no presente sem qualquer referência ao passado do que está fazendo? Bem, aqui estão alguns motivos porque não.

Para alguns cientistas da religião, muitos dos quais inspirados por interesses teológicos, enfatizar a necessidade do estudo da história dos estudos sobre a religiáo parece irrelevante e até mesmo ofensivo. Comumente eles já estão passionalmente engajados, debatendo-se com vários problemas existenciais, políticos e sociais prementes, tais como raça, gênero, pobreza, violência etc. Já é difícil mantê-los interessados nas dimensôes comparativas e fenomenológicas da ciência da religiáo em si, sem esperar que se comprometam com a história dos estudos da religiáo. O tipo de pensamento deles é o que fez o estudo das religióes da Índia nas décadas de 1960 e 1970 se inclinar a uma preocupação tanto de Gandhi enquanto um mentor para o nosso próprio protesto político antiguerra ou náo violento quanto a um interesse pela experiência iogue e mística como confirmação de experiências contraculturais sobre a experimentação das drogas - ou, com a mesma frequência, na "desintoxicação" delas.

\footnotetext{
Doutor em Ciência da Religiáo pela Universidade de Birmingham (Inglaterra). Professor emérito do departamento de Ciência da Religiâo da Universidade da Califórnia, Riverside (Estados Unidos). ORCID: 0000-0001-7702-7891 - contato: ivan.strenski@ucr.edu.

** Doutor em Ciência da Religião (PUC-SP). Bolsista PNPD/CAPES pelo PEPG em Ciência da Religião da PUC-SP. ORCID: 0000-0001-7180-299X - contato: Alstern@pucsp.br.
} 
Serei o primeiro a admitir que, talvez, os engajados entre nós estão certos em não se importar com a história dos estudos da religião? Devemos nos lamentar, por exemplo, que Martin Luther King Jr. tenha passado a maior parte do tempo estudando ética social e teologia cristã na Universidade de Boston, ao invés da história dos estudos da religião? Assim como Martin Luther King, somos pressionados pelas demandas dos problemas atuais e julgados por nossas reações a eles pelos valores de hoje.

Dessa forma, dada a força desse inebriante compromisso político e engajamento moral, estudar a história da ciência da religião parece apenas incomodar: aqueles homens mortos da história da ciência da religião têm agora a audácia de insistir em que utilizemos nossa valiosa juventude prestando atenção aos seus interesses ultrapassados. Sério? Quem esses homens mortos pensam que são?

Mas podem existir outros menos inclinados à teologia ou a serem agentes sociais de mudanças do que, digamos, em promover a ciência da religião em um sentido acadêmico. Esses concordam comigo sobre a necessidade de entender a história dos estudos da religião, porque seus interesses são primordialmente acadêmicos, e não militantes. Mas duvido que muitos deles estejam preparados para seguir as minhas recomendaçóes. Alguns podem dizem, "Claro, seria legal saber a história dos estudos da religião, assim como é legal guardar fotografias de nossos avós e bisavós em alguma gaveta de mesa para uma consulta ocasional. Valeu pela lembrança; e só”. Para eles, o que importa é o quão relevante é a história ou não.

Então outro grupo, acenando a cabeça, pode acrescentar: "Claro, seria legal saber a história dos estudos da religião - e pode até ser que ela seja significativa para certos propósitos, mas quero continuar na tarefa principal de estudar religião. Se me dedicarei à pesquisa, minha prioridade máxima deve ser algo prático, como a metodologia - que métodos utilizar na ciência da religião. Não quero gastar meu tempo aprendendo sobre como a religiaao foi estudada no passado!". Quer dizer, embora os físicos leiam sobre a física newtoniana, eles realmente se importam com a biografia de Newton? São relevantes para eles as particularidades religiosas e políticas do tempo de Newton, e sua imersão nelas? Será que nós, como sociedade e até mesmo enquanto disciplina acadêmica chamada ciência da religiáo, enriqueceríamos nosso conhecimento sobre o islá ou o budismo por causa da sensibilidade histórica ao percurso tomado pelo estudo dessas religióes em comparação, digamos, com o conhecimento adquirido sobre o islã ou o budismo graças a Wilfred Smith ou Stanley Tambiah, respectivamente? Por isso, mais uma vez, pergunto em nome dos anuentes e dos céticos: quem, de fato, esses homens mortos dos estudos da religiáo pensam que são?

Para além de argumentar que o conhecimento é sempre um bem em si e que, portanto, tal iniciativa de estudar a história dos estudos da religião na verdade não precisaria de defesa, quero tentar expor as razóes mais convincentes para os cientistas de religiáo estudarem ou levarem a sério a história dos estudos da religião. Em suma, quero deixar algumas novas marcas na ideia de que a história dos estudos da religiáo é importante para a ciência da religião, porque o conhecimento do passado muitas vezes molda como vivemos e agimos no presente. Quero argumentar não apenas que o que fazemos hoje repousa sobre o que aconteceu ontem, mas também sobre o que acreditamos que aconteceu, como conceituamos o que acreditamos que aconteceu, e o que de fato aconteceu no passado. 
Para aqueles que se encontram comprometidos existencialmente e querem mudar a sociedade, espero lembrá-los do que já sabem: o estudo da história pode reformular nossas definiçóes do presente, e assim se tornar decisivo em promover mudanças no presente. É por isso que muitas vezes ouvimos queixas passionais contra aqueles que "reescrevem a história". Ou, de maneira mais benigna, contra aqueles que consideram como o recente trabalho sobre a história das mulheres do cristianismo no Ocidente muniu reformadoras feministas com armas para desafiar instituições religiosas históricas, como o sacerdócio masculino. Para aqueles que são obcecados em estudar o objeto religião com pouco ou nenhum entusiasmo pelas glórias da metodologia e da história, espero persuadi-los a seguir a ideia que alguns já podem adotar amplamente: que a "religião" que buscam estudar é, em si, um conceito histórico. Como tal, o significado comum de "religiáo" mudou ao longo dos anos, de modo a excluir ou incluir fenômenos que se pensava serem ou não essencialmente religiosos. É somente através de algum trabalho histórico sério e de uma autocrítica analítica que se pode ter certeza do que se busca estudar na ciência da "religiáo". Quando os críticos de Durkheim o atacaram por incluir exemplos budistas e primitivos em seu livro As formas elementares da vida religiosa, eles o fizeram em parte porque se recusavam a classificá-los como "religióes", assim como hoje estamos enfadados com toda a controvérsia de "culto-seita-religião".

Mas se a história da ciência da religião parece, ao menos agora, fazer certa diferença na forma como estudamos a religião, que tipo de história fará isso?

Temos a sorte de viver em uma época em que a própria história tem sido uma das disciplinas mais criativas das ciências humanas. A história tem sido assim criativa principalmente por causa de dois desenvolvimentos. O primeiro é o da história crítica das mentalidades, iniciada com os historiadores da escola dos Annales do início do século XX e, de certo modo, sucedidas por historiadores como Michel Foucault e Edward Said. O segundo é o do movimento do novo historicismo, associado a nomes como Quenti Skinner, historiador britânico das ideias.

Foucault, Said e os Annales nos fizeram considerar, entre outras coisas, a proposição de que as formas de ver o mundo são, elas próprias, objetos de investigação histórica. A história não é mais apenas sobre as maquinações de diplomatas ou sobre a movimentação de exércitos, mas também sobre as categorias que utilizamos para pensar as coisas. $\mathrm{Na}$ ciência da religião, isso poderia ser traduzido nos estudos da palavra "religião" tais como o livro de 1990 de Peter Harrison, "Religion" and the religions of the English Enlightenment-, ou nos estudos da palavra "mito" (ao invés de mais um compêndio das mitologias mundiais), dos quais cito minha própria obra Four theories of myth in twentieth-century history.

Sem julgarmos seu valor final, consideremos apenas o trabalho de Foucault, Edward Said ou a efervescência entre historiadoras com uma inclinação feminista. Aqui estão aquelas pessoas comprometidas não apenas em contar a história do passado, mas em fazê-la criticamente, demonstrando como o passado tem sido sistematicamente - embora, algumas vezes, involuntariamente - construído pelos métodos utilizados para se apreender o passado. Vivemos numa época em que devemos ser sensíveis às maneiras pelas quais nossas crenças sobre a natureza da religiáo e sobre a natureza da história da religião moldaram o que fizemos vir a ser a religião e sua história. $\mathrm{O}$ trabalho de Said 
sobre o orientalismo, por exemplo, parece um bom caso de como a história dos estudos da religião pode importar para a ciência da religião. Dessa forma, principalmente com caso do islá, Said tentou mostrar o significado cultural e social mais amplo do caminho pelo qual os historiadores construíram a categoria "o Oriente" como algo a ser estudada de uma maneira específica. Independente de seus resultados, Said deve nos deixar cautelosos sobre como nossos compromissos podem moldar a maneira como apreendemos e conceituamos o outro e, portanto, como as políticas práticas e as atitudes sociais podem ser orientadas como resultado disso ${ }^{1}$. No caso do budismo, consideremos também como avançou a nossa compreensão do budismo moderno e contemporâneo no Sri Lanka com o trabalho de Richard Gombrich e de outros, em comparação aos estudiosos do século XIX que concebiam o budismo teravada como uma espécie de budismo "protestante", o que moldou a perspectiva de uma geração de acadêmicos. E mesmo que eu tenha elogiado Wilfrid Cantwell Smith por sua obra acadêmica de primeira ordem sobre o islá, não me esqueci de seu trabalho pioneiro $O$ sentido e o fim da religião, de análise histórica, que teve muita influência em levantar a questão da natureza histórica da religião, tanto da terminologia básica quanto do próprio termo "religiáo" em si.

Seguindo os pressupostos da abordagem de Said e outros, a história dos estudos da religiáo, se feita criticamente, desempenha um papel fundamental em ajudar a nos comprometermos com a ciência da religião, em conseguirmos adquirir mais do que o nosso próprio quadro conceitual. A conceituação é, portanto, o que fazemos quando falamos da religiáo como "o ópio do povo", como "relação da humanidade com o sagrado", como expressão da "preocupação última" da humanidade e assim por diante. A conceituaçáo é o ato cognitivo mais fundamental que podemos realizar em nossos estudos. Para apreender os materiais religiosos, precisamos primeiro conceb $\hat{e}$-los de certa forma. Como resultado, em geral a história dos estudos da religião é importante.

Agora, dada a história específica do Ocidente, uma das coisas de importância central para nós tem sido a religião. Mas dada também essa história peculiar, uma das questóes mais controversas tem sido qual é ou deveria ser a natureza da religiáo. Consideremos meramente nossas discussões atuais sobre a demarcação dos limites do que chamamos de "religiáo" - objeto endêmico para a cultura ocidental. Tomemos, por exemplo, a chamada distinção entre "culto" e "religião", recentemente apresentada na vida cívica no cerco de Waco, ou ainda mais recentemente em Who gets to define religion?, de Larry Shinn, no número de julho da Religious Studies Review, ou para voltar ao debate teológico tradicional, a suposta distinção entre "religião" e "Palavra" ou "kérygma". E assim, na

1 Contudo, a principal desvantagem de Said e outros frente às atitudes críticas e céticas encorajadas por Foucault é que eles podem gerar uma nova ortodoxia e correr o risco de colocar a mão morta do cinismo no fazer da ciência da religiâo. Infelizmente é bastante comum em nosso mundo acadêmico, afligido pelo politicamente correto, de encontrarmos regularmente a alegação de que apenas membros de subgrupos específicos podem pesquisar esses subgrupos, e que aqueles que não fazem parte não podem. Seja explicitamente ou implicitamente, isso equivale a dizer que por um escritor poder ser classificado como homem, branco ou europeu, isso é evidência suficiente para justificar que seu trabalho será necessariamente e profundamente tendencioso em termos dos interesses desse subgrupo social. Embora se possa entender como esse atalho economiza tempo e energia em ler e estudar seriamente os autores e trabalhos envolvidos, dificilmente alguém pode ficar satisfeito com uma leitura tâo ampla dos escritores. Em particular, seria bom lembrar que o próprio Said distingue entre estudiosos do islá como Maxime Rodinson e Louis Massignon - ambos igualmente brancos, homens e europeus - de outros que ele acredita trabalharem no estilo orientalista clássico. 
história crítica dos estudos da religião importa, em particular, o que é considerado ser "religiáo" em si - algo certamente fundamental a todos nós. Mas como esclarecemos nossos conceitos fundamentais?

Sempre que utilizamos noçôes teóricas como "mito", "ritual", "misticismo", "religiáo" etc., devemos ter claro como as empregamos. Podemos fazer isso inicialmente por simples introspecção ou analisando nossa escrita e discurso. Temos aqui a análise conceitual ou metodológica mais comum na ciência da religião, o que fazem pessoas como Hans Penner, Robert Segal ou Donald Wiebe. Tomando a categoria "religiáo" como exemplo, provavelmente descobriríamos que adotamos "religião" derivando, quer seja deliberadamente ou não, de alguma definição de um dos teóricos do campo - Marx, Durkheim, Mircea Eliade etc. Mas deveria surgir a questão sobre se realmente estamos trabalhando como eles queriam que alguém trabalhasse com "religiáo". Quero dizer, a menos que eu apenas queira "voar" por conta própria, devo querer saber se estou realmente lidando com "religião" da maneira que preciso objetivar - como um Eliade, como um Durkheim etc. Logo, deveríamos querer, entáo, verificar como é que eles próprios utilizaram o termo "religião".

No momento em que se torna importante conhecer o "outro" histórico é que a história entra em cena. Não é suficiente assumir, adivinhar ou imaginar o que eu faria se eu fosse Durkheim ou Eliade. Devemos realmente ter alguma base - os melhores fundamentos que podemos ter - para assumir que sabemos o que eles queriam dizer quando propuseram certas construçóes teóricas em torno do termo "religiāo". Não consigo pensar em fundamentos melhores para entender o que um teórico quis dizer do que conhecer suas reais intençôes, o significado de sua linguagem e conceitos na circunstância em que ele escreveu o que escreveu, o contexto real de vida da teoria ou ideia teórica em questão. Juntar tudo isso para ajudar na compreensão é o fazer história da maneira que chamo aqui como "novo historicismo".

Assim, no caso de Durkheim, por exemplo, nossa compreensão da sua utilização do termo "religião" (e mais ainda "sagrado"), sua especial afirmação da natureza social da "religiáo" tal como a entendia, teria algo a ver com a sua localizaçáo em vários campos semânticos. O mundo acadêmico e cultural do seu tempo era fortemente dominado por protestantes liberais extremos, judeus universalistas e humanistas religiosos românticos. Para eles, o termo "religião" estava intimamente ligado a várias tradições de discurso teológico, como as prevalecentes na França desde o Iluminismo: o discurso da religiáo natural, o discurso da religiáo como uma questão de consciência privada, e o discurso nacionalista da religiáo como alma da nação. Durkheim teve que ponderar que quando o termo "religiáo" era utilizado em sua época, ele tinha, até certo ponto, tais associações semânticas teístas, individualistas e nacionalistas. Poderíamos perguntar se sua teoria da religião poderia, entâo, de alguma forma ter "dialogado" com (ou contra) essas teologias e teorias da religião - mesmo que virtualmente ele não diga nada explicitamente sobre elas. Se, como se vê, a noção de religiáo de Durkheim estava historicamente em tal "diálogo", isso explicaria certas coisas sobre por que Durkheim concebia a religiāo como ele concebia. Suas ligaçôes com o nacionalismo explicariam porque Durkheim sentiu a necessidade de colocar a religiáo como uma coisa eminentemente social, em vez de algo privado e individual. Como liberal, Durkheim deve ter sido levado a adotar a 
apologética teísta escondida na linguagem secular dos teístas. Em vez disso, ele rejeitou esse ideal de uma religiosidade a priori nas pessoas, bem como a bondade a priori da religiaao. A religião não era algo que simplesmente estava ali, enraizada em nossa consciência mais profunda, em nosso refúgio interior em um mundo sem coração. Era algo poderoso e quase literalmente "elétrico", algo que tinha que ser estimulado e trabalhado - por exemplo, através de rituais. Para Durkheim, um nacionalista fervoroso, esse era o único tipo de religiáo que valia alguma coisa. Esses outros tipos - aqueles associados ao tépido cristianismo liberal de seus dias - eram inadequados às tarefas exigidas pela época. Eram eles as religióes falsificadas, e não as chamadas "religiôes sociológicas" imaginadas por Durkheim.

É triste dizer que mesmo as melhores histórias dos estudos da religião que temos hoje não funcionam dessa forma crítica e, no processo, podem tender a prestar um mau serviço ao campo porque, ao fazer história de certa maneira, não dão sentido às razóes pelas quais alguém pode ter pensado no modo que fez. Essas histórias antiquadas não trazem o passado vivo.

Se, por exemplo, quiséssemos explicar como surgiu a teoria de Durkheim sobre a religião, precisamos compreender no mínimo (sem dúvida mais do que isso) como ele abordou certas comunidades-chave. Parte, pelo menos, do sucesso de seu programa de explicação dependeria de convencer certos públicos a aceitar as explicaçóes dadas. E, em certo sentido, a aceitação estaria relacionada aos interesses do grupo em questáo.

Por melhor que seja o esforço do Explaining religion de Sam Preus, por exemplo, a obra é limitada nestas e em outras questóes semelhantes. Quero me concentrar em dois aspectos desse trabalho: sua abordagem internalista e whiggish. A história internalista se concentra em textos e não em contextos, nos seus argumentos e lógica internos, na passagem não mediada de grandes ideias de um grande pensador para o outro. Ao mesmo tempo, a história internalista de Preus tende também a ser whiggish. A história whig ${ }^{2}$ nos encoraja a vermos a história das ideias como uma espécie de desfile triunfante de noçóes progressistas, marchando desde as suas origens humildes, derrotando concorrentes inferiores por força do seu "valor intrínseco" e provando ser dignas da lealdade e adesão humanas. Assim, a sociologia durkheimiana se tornou uma força dominante no pensamento francês por causa de seu valor intrínseco, porque enfrentou seus concorrentes e os encarou de frente!

No entanto, se quisermos mostrar como a história dos estudos da religião é importante para a ciência da religiáo, temos de construir esta história de outra forma - uma combinação de formas externalistas e historicistas. O externalismo leva a sério a forma como as ideias são "corporificadas" ou tornadas possíveis pela sua localização social. O historicismo se centra em como as ideias falam para uma determinada faixa etária e refletem os projetos intencionais dos seus criadores. Do ponto de vista da combinação entre externalismo e historicismo, a história dos estudos da religiáo se

2 N.T.: História whig (derivado da filosofia política whiggismo, do Reino Unido) é um termo aplicado às histórias que apresentam o passado como uma marcha inexorável do progresso até o Iluminismo. É empregado de forma pejorativa na história da ciência para se referir às historiografias que se concentram em cadeias bem sucedidas de teorias e experiências que levaram à ciência atual, ignorando as teorias que náo deram certo ou que foram abandonadas. 
torna uma história de ideias e práticas que competem pelos interesses das pessoas em certos contextos sociais competindo por uma "racionalidade social". Acima de tudo, fazer uma história externalista significa estar atento a questóes de causalidade social no domínio das ideias, enquanto o historicismo procura causas dentro do contexto de origem das ideias. Logo, é uma forma da história dos estudos da religião que pode ser importante para a ciência da religião, ajudando a compreender o sucesso ou o fracasso dos modos de explicação em termos de como eles abordaram as questóes valorizadas pelas pessoas nesses contextos. Dessa forma, quer objetivemos sistematicamente nos afastar das suas ideias ou persegui-las, seríamos capazes de fazer isso num sentido real. Quando se trata de compreender o pensamento do outro, nada supera o real conhecimento sobre o outro.

Agora, alguém pode perguntar por que pareço táo apaixonado por essa busca do conhecimento histórico real do "outro"? O que é táo ruim sobre o velho modelo de história intelectual de uma linhagem de grandes homens falando sobre os ombros de seus sucessores e sussurrando nos ouvidos da próxima geração? O que há de tão errado em abordar um autor em termos do que é lembrado de seu pensamento? O que é errado aqui é de natureza moral - essas abordagens das figuras históricas equivalem ao que um colega chamou de "trapacear os mortos" -, de impor nossas opinióes àqueles incapazes de se defenderem.

Todos sabemos como a história pode por a mão morta sobre os esforços do presente. De fato, essa foi uma das razóes pelas quais nossos colegas militantes se opuseram à história do estudo da religiáo em primeiro lugar. Ela pode exigir tanto do pensador criativo ou ativista moral que a própria criatividade é retida por ter que atender constantemente às tarefas que a máo morta do passado tem a oferecer. Podemos até esquecer como ter nossos próprios pensamentos e sentimentos, e apenas recitar o que os outros disseram. Estar em conversação com o passado pode, portanto, vir à custa de se estar em conversação com o presente, ou à custa pensarmos por nós mesmos.

Mas o mesmo acontece no contrário, especialmente nesses dias de preocupaçóes engajadas pela relevância e tal. Às vezes, é a "mão morta” do presente que póe em perigo a criatividade do pensamento, mesmo entre os historiadores professos da ciência da religião.

A primeira maneira pela qual o presente pode colocar uma "mão morta" sobre o passado é apropriando-se do (recriando o?) passado de uma forma conveniente ao nosso estado atual de conhecimento, ou fazendo do passado um reflexo autojustificador de nós mesmos. Aqui, tentamos tratar o passado como uma antecipação especial do que nos interessa. Podemos ter, por exemplo, alguma ideia que gostaríamos de levar a frente. Assim, tentamos ver nas palavras e intençóes de um pensador clássico um reflexo dela para, muitas vezes, justificá-la.

Durkheim, por exemplo, fala bastante sobre símbolos. E talvez porque eu possa ter uma afeição especial pelo ditado teológico de se ir além do literal, ao espírito da palavra, eu suponho que Durkheim estava igualmente engajado nessa busca. Esse caminho está equivocado, como mostrarei agora, e se baseia na ignorância. Em resposta, é a ignorância da história que póe em perigo a criatividade e o trabalho construtivo. Dissipar esta ignorância é tarefa do novo historicismo. 
Permita-me dissertar sobre a tentativa de Sam Preus de colocar Durkheim numa tradição de análise simbólica mais familiar aos cientistas da religião, em sua história recente e justamente aclamada da tradição naturalista dos estudos da religiáo, a obra Explaining Religion. Uma característica fundamental da análise de Preus sobre a abordagem de Durkheim sobre a religiáo é o que veio a ser conhecido como a abordagem simbólica de Durkheim acerca da religiáo. Para Durkheim, "explicar a religiáo" significava ir "além do literal" (Preus, 1987, p. 163), ao verdadeiro significado. Neste sentido, o "literal" era apenas um "símbolo" da realidade subjacente - para Durkheim, "Deus" era apenas um "símbolo" para "sociedade". Mas Preus quer saber que tipo de abordagem foi essa, e os motivos e intençóes mais profundos de Durkheim? Seria ele talvez algum tipo de crítico antifundamentalista do conservadorismo religioso? Um antipositivista repelido pela tirania dos fatos? Ou Durkheim estaria apenas fazendo um estranho tipo de "exegese bíblica" do espírito contra a lei, como sugere o próprio Preus (1987, p. 163)? Como explicar por que Durkheim achou que seria amplamente aceitável caracterizar sua explicação pela alegoria de "ir além do literal"? Como em muitas coisas relacionadas ao pensamento, a pergunta mais difícil é muitas vezes apenas saber (ou talvez melhor, decidir) o que é que estamos observando.

No fim, a abordagem de Preus a esse problema de saber o que Durkheim quis dizer se resume a dizer que ele "se lembra" de certas coisas quando lê Durkheim. Ele "se lembra da fórmula clássica da hermenêutica bíblica, que a palavra mata [...]” (Preus, 1987, p. 163, grifo meu). Mais adiante, nesse sentido, Preus novamente fala de como as características do pensamento de Durkheim lembram um "estilo humeano" de pensamento, ou uma "estrutura tyloriana" (Preus, 1987, p. 168), e assim por diante.

$\mathrm{O}$ que se pode dizer sobre isso? Se realmente queremos investigar as influências da teoria de Durkheim, então procuraremos aqueles que de fato exerceram influência sobre Durkheim - ao invés de deixar que nosso próprio conhecimento seja a medida do que moldou as mentes do passado, ao invés de deixar que os caprichos do que somos lembrados no presente guiem a "mão" do que escrevemos sobre o passado. Portanto, respondo a Preus o seguinte: primeiramente, longe de ser um empirista humeano, por exemplo, Durkheim era um racionalista filosófico e, provavelmente, uma espécie de neohegeliano, que só uma vez se referiu a Hume; em segundo lugar, ele estava mais preocupado em rever do que em revisitar Comte; em terceiro lugar, Durkheim tinha Frazer, Albert Réville e Robertson Smith muito mais em mente do que Tylor; e, por fim, não consigo encontrar qualquer referência a Vico em sua obra. Preus também não enfatiza (e em alguns casos nem identifica) os pensadores que Durkheim realmente levava em consideraçáo, como Robertson Smith, Renouvier, Hamelin, Harnack e assim por diante. Se coisas do pensamento de Durkheim "lembram" Kant, façamos então um levantamento profundo para descobrirmos que tipo de Kant (neo?) Durkheim poderia ter aprendido, e com quem ele aprendeu suas liçôes? Podemos fazer muito mais do que falar de como as ideias de Durkheim nos lembram ou se assemelham formalmente a um "estilo humeano" de pensamento, ou a uma "estrutura tyloriana" (Preus, 1987, p. 168) e assim por diante. Poderíamos ver o que Durkheim estava fazendo de verdade, quem de fato ele leu, e com quem ele conversou e debateu. Isso significa também que precisaríamos conhecer as intenções de Durkheim e os textos que ele lia em seu contexto. Se 
soubéssemos quais eram essas informaçôes, poderíamos compreender a sua abordagem para com a religiáo em termos da realização de certos desejos que Durkheim poderia ter tido, e da realizaçáo de certos objetivos, propósitos e afins que lhe eram caros.

Se não fizermos essa pequena cortesia para com os mortos, nós próprios estaremos a estender uma máo a partir do presente - neste caso, uma máo mortal - e a moldar o passado ao nosso gosto. Ao fazer isso, de fato "matamos" os pensamentos do passado, sobrepondo-lhes os nossos próprios pensamentos. Ninguém sequer ousaria fazer o mesmo tipo de sobreposição hoje em dia com uma cultura do terceiro mundo. Entáo por que fazemos isso com tanta impunidade com o passado? A única resposta que posso oferecer é que fazer ciência é um trabalho árduo, e que não estamos preparados a esse tipo de trabalho necessário para fundamentar e defender os nossos próprios pontos de vista teóricos. Por isso, tentamos fazer com que Durkheim faça o trabalho pesado por nós. Imputamos-lhe opiniôes que, na verdade, são nossas.

Deixe-me mostrar o que já podemos entender sobre as tentativas de Durkheim de "ir além do literal", usando uma abordagem que respeita o passado, em vez de trapaceá-lo, ou simplesmente utilizá-lo como uma parede em branco ao graffiti de nossas imaginaçóes. Uma primeira pergunta deve ser se Durkheim estava sozinho em ter aspiraçôes de "ir além do literal". Ou podemos entender Durkheim em termos de sua participação em uma empreitada maior e, assim, explicar parcialmente o que ele quis dizer com esses termos?

Neste sentido, mesmo que muitos façam turnos errantes - Preus já incluso -, eles sugerem erroneamente que devemos olhar para a interpretação "simbólica" de Durkheim sobre a religiáo dentro do contexto de outras utilizaçōes do símbolo na época. Preus (1987, p. 161) preenche essa lacuna pela hermenêutica bíblica ou pelo método alegórico. Ambos são esforços interessantes, mas refletem muito pouco em termos de como era a realidade de vida de Durkheim. Captar os contextos que permitem que as ideias de Durkheim façam sentido não é apenas uma questão de fazer uma ligação inteligente a algo que nos "lembra" a abordagem simbólica de Durkheim frente aos textos das doutrinas religiosas. Precisamos mostrar que encontramos o paralelo correto. Sendo assim, se quisermos explicar a que se referia a explicaçáo de Durkheim sobre a religião, é importante compreender o que Durkheim realmente quis dizer ao defender uma abordagem simbólica da religião.

Se a literatura de ideias religiosas está em questão, por que náo olhar entáo para como e por que os simbolistas religiosos procuravam "ir além do literal"? Acontece que justamente quando Durkheim estava desenvolvendo sua interpretação simbólica das ideias e práticas religiosas, todo um movimento contemporâneo de teólogos franceses estava envolvido em leituras simbólicas autoconscientes de suas próprias tradições. Conhecidos amplamente como "modernistas" religiosos, neles se incluíam figuras como os católicos Marcel Hebert e Alfred Loisy, os judeus Salomon Reinach e Sylvain Levi, assim como os protestantes Albert Reville, Jean Reville, e Augusto e Paul Sabatier. Além disso, eles eram tão bem conhecidos dos durkheimianos quanto o grupo de Durkheim era conhecido por eles. Cada um revisava as principais obras dos outros, debatendo frequentemente sobre questóes de interesse comum em grupos de discussão intelectual ou como colegas nos conselhos da vida acadêmica. 
Agora podemos mostrar como a história dos estudos da religião pode fazer uma diferença para a ciência da religião. Ela nos fala sobre a própria religião. Para cientistas da religiáo, ligar Durkheim aos modernistas religiosos explora o que sabemos sobre seus projetos e aspiraçóes de fundar uma religião civil francesa, em conexão com a sua adesão à religião de humanidade e à sacralidade do indivíduo. $\mathrm{Na}$ verdade, podemos explicar melhor o papel de Durkheim no que diz respeito à religião de humanidade como um "modernizador", como os teólogos modernistas que procuraram renovar suas próprias religiōes. Dar mais sentido a essa visão é a estreita ligação entre liberalismo e modernismo, tanto na esfera política quanto na esfera religiosa. O liberalismo político de Durkheim, seu individualismo "social", estava, entre outras coisas, internamente ligado ao seu programa de modernização da religião até então muitas vezes egoísta da humanidade. O liberalismo precisava ser repensado para que a comunidade tivesse um lugar central na sua compreensão.

Gostaria de concluir com uma observação sobre o resultado desse pequeno passeio no mundo do pensamento de Durkheim. Comecei por apresentar a queixa daqueles que se opóem ao papel da história dos estudos da religião na ciência da religiáo. Para eles, por que pesquisar sobre como a religiáo era estudada quando nós realmente queremos estudar religiáo? Bem, uma resposta tardia e parcial aos meus estimados colegas nesse campo é que pode ser precisamente fazendo a história dos estudos da religião que podemos fortalecer o nosso conhecimento da religião do final do século XIX e início do século XX (e mais além). No caso dos durkheimianos, encontrarmos um caso notável em que a própria religião pode ser vista como um agente na história da ciência da religião, porque foi um agente central na história da época.

\section{Referências}

PREUS, J. Samuel. Explaining religion. New Haven: Yale University, 1987.

Recebido: 30 de agosto de 2019.

Aprovado: 22 de setembro de 2019. 